\title{
The Physics of Phenomenological Structuralism
}

\author{
Paul C Mocombe* \\ West Virginia State University, The Mocombeian Foundation, USA
}

*Corresponding author: Paul C Mocombe, West Virginia State University, The Mocombeian Foundation, USA.

Received Date: July 21, 2020

Published Date: July 31, 2020

\begin{abstract}
This work highlights the physics and metaphysics of the universe (multiverse) according to Paul C. Mocombe's theory of phenomenological structuralism. The author posits that phenomenological structuralism offers an emergent metaphysical materialist account regarding the formation and perpetuation of the multiverse, consciousness, and society.
\end{abstract}

Keywords: Structurationism; Praxis, Panpsychism; Social Class Language Game; Phenomenological Structuralism; ORCH-OR Theory; Univon Multiverse Hypothesis; Free-will; Determinism; Haitian Epistemology

\section{Introduction}

This work highlights the physics and metaphysics of the universe (multiverse) according to Paul C. Mocombe's theory of phenomenological structuralism. The author posits that phenomenological structuralism offers an emergent metaphysical materialist account regarding the formation and perpetuation of the multiverse, consciousness, and society. Paul C. Mocombe's structurationist theory of phenomenological structuralism, building on and synthesizing a form of M-theory with, mathematical elements of univon multiverse hypothesis, the quantum computation of ORCHOR theory, structurationism, and the multiverse ideas of Haitian ontology/epistemology and quantum mechanics abductively posits that consciousness is a fifth force of nature, a quantum material substance/energy, psychion, the phenomenal property, qualia or informational content, of which is recycled/entangled/ superimposed throughout the multiverse and becomes embodied via the microtubules of brains and multiple worlds to constitute mind. Mind, in turn, is manifested in simultaneous, entangled, superimposed, and interconnecting material resource frameworks, multiple worlds, as praxis or practical consciousness of organic life, which in-turn becomes the phenomenal properties, qualia, of material (subatomic particle energy, psychion) consciousness that is recycled/entangled/superimposed throughout the multiverses. In this sense, the physics of phenomenological structuralism posits an emergent materialist multiverse that is superimposed and entangled like consciousness.

\section{Background of the Problem}

Two views regarding the origins and nature of consciousness and the universe dominate contemporary physics. On the one hand, are theorists who view consciousness as fundamental to the universe and a by-product of a supernatural or cosmic creator who fine-tuned the universe for life and intelligent beings [1]. On the other hand, are materialists/physicalists who view our universe as a random product of chance among a plethora of multiverses some of which have life while others do not. Consciousness, in the latter, is simply a product of the mechanical and chemical processes of the brain imposing meaning onto a meaningless and absurd universe and the world.

Both positions are problematic when it comes to understanding the constitution of consciousness and the universe/multiverse. 
The former presupposes that consciousness in the form of a creator created the multiverse, and beings with consciousness are a perception in the mind of said creator (s). The latter assumes that consciousness is simply a chemical illusion of the mechanical brain interacting with matter. Although this latter position gives a mechanical understanding regarding the constitution of the universe/multiverse, it fails to explain the "hard problem" of consciousness (David Chalmers's term), i.e., the subjective experiences of consciousness. For me, building on Paul C. Mocombe's [2] metaphysical materialist theory of phenomenological structuralism, consciousness is emergent and comes to constitute a fifth force of the multiverse, with phenomenal properties, qualia, following matter random constitution, evolution, and disaggregation from the original four forces of nature, i.e., the weak and strong nuclear forces, gravity, and electromagnetism. In other words, consciousness is an emergent fifth force of nature, a quantum material substance/energy, psychion, the phenomenal properties, qualia, of which are recycled/entangled/superimposed throughout the multiverse and becomes embodied via the microtubules of brains and multiple worlds to constitute mind. Mind, in turn, is manifested in simultaneous, entangled, superimposed, and interconnecting material resource frameworks, multiple worlds, as praxis or practical consciousness of organic life, which in-turn becomes the emergent phenomenal properties, qualia, of material (subatomic particle energy, psychion) consciousness that is recycled/entangled/superimposed throughout the multiverses following matter disaggregation. Consciousness from this understanding is emergent and material following the constitution of space/time, which is fundamental.

In the human sphere, consciousness refers to subjective awareness of phenomenal experiences (ideology, language, self, feelings, choice, control of voluntary behavior, thoughts, etc.) of internal and external worlds emerging in space/time. The academic literature "describes three possibilities regarding the origin and place of this (human) consciousness in the universe: (A) as an emergent property of complex brain neuronal computation, (B) as spiritual quality of the universe, distinct from purely physical actions, and (C) as composed of discrete 'proto-conscious' events acting in accordance with physical laws not yet fully understood" [3]. The latter position, (C), represents the ORCH-OR ("orchestrated objective reduction") theory of Stuart Hameroff and Roger Penrose (2014), which includes aspects of (A) and (B), and posits that "consciousness consists of discrete moments, each an 'orchestrated' quantum-computational process terminated by... an action [,objective reduction or $\mathrm{OR}$,] rooted in quantum aspects of the fine structure of space-time geometry, this being coupled to brain neuronal processes via microtubules" (pg. 70). In this view, the understanding is that a proto-conscious experience existed in the universe, panpsychism, and as a result of emergent structures of the brain it (proto-conscious experience, psychion) became embodied and evolved as a result of quantum neuronal computations of "brains." "Brains", in the human form, as a part of the universe/multiverse, are used to both experience being-in-theworld and to capture the nature of reality as such in the form and emergence of the practice and language of science.

Paul C. Mocombe's [4] structurationist sociology, phenomenological structuralism, which attempts to resolve the structure/agency problematic of the social sciences, builds on the ORCH-OR theory and panpsychism of Hameroff and Penrose, while holding on to the multiverse hypothesis of quantum mechanics (M-theory and the mathematics of univon multiverse hypothesis) and Haitian ontology/epistemology, which the authors reject because it is not "a more down-to-earth viewpoint," to capture the nature and constitution of the universe/multiverse as such. (Hameroff and Penrose, [2]. For Mocombe [4], quantum superposition, entanglement, wave-function realism, and evidence in Haitian Vodou of spirit possession, which represent ancestors from a parallel world, Vilokan, of the earth's of which we ought to pattern our behaviors and structures, are grounding proofs for the acceptance of the multiple worlds hypothesis of quantum mechanics. Within the latter hypothesis, the understanding is that "each possibility in a superposition evolves to form its own universe, resulting in an infinite multitude of coexisting 'parallel' worlds. The stream of consciousness of the observer is supposed somehow to 'split', so that there is one in each of the worlds-at least in those worlds for which the observer remains alive and conscious. Each instance of the observer's consciousness experiences a separate independent world and is not directly aware of any of the other worlds" (Hameroff and Penrose, 2014, pg. 50). It is within this multiple world hypothesis, physics, that Mocombe constitutes his understanding of the emergence of the material multiverse and the notion of consciousness in each of the universes according to his theory of phenomenological structuralism. For Mocombe, consciousness is an emergent fifth force of nature, a quantum material substance/energy, psychion, the phenomenal properties, qualia, of which are recycled/entangled/superimposed throughout the multiverse and becomes embodied via the microtubules of brains. It (consciousness) is manifested in simultaneous, entangled, superimposed, and interconnecting material resource frameworks as mind or embodied praxis or practical consciousness, which in-turn becomes the phenomenal properties, qualia, of material (subatomic particle energy, psychion) consciousness that is recycled/entangled/superimposed throughout the multiverses following matter disaggregation [5-10].

In other words, I adopt from the "membrane theory" model of Lisa Randall and Raman Sundrum (1999) the assertion, in keeping with the logic of Haitian Vodou, that there might be an additional dimension on the cosmological scale, the scale described by general relativity, which gives rise to four dimensional multiverses within it. Our universe is embedded in a vastly bigger five-dimensional space (the four-dimensional space of relativity, plus a fifth dimension for the subatomic forces including consciousness), a kind of 
super-universe. Within this super-space, our universe is just one of a whole array of co-existing universes (Haitian Vodou only accounts for our universe and its parallel), each a separate fourdimensional bubble within a wider arena of five-dimensional space where consciousness (a subatomic force) is recycled/entangled/ superimposed between the species of the five-dimensional superspace, i.e., superverses, and their four-dimensional multiverses Figure 3.

The origins of consciousness and the multiverse within this phenomenal structural paradigm is emergent, and not the product of a supreme creator or god. For this position, I build on the mathematics of Richard Gauthier (2020) in his "univon multiverse hypothesis." Unlike Gauthier, who holds on to God or a supreme creator to account for the origins and nature of consciousness within the multiverse, I do not. According to Gauthier's (2020) model, identical univon quantum particles, produced from a univon quantum field, created not only our universe but also many other identically fine-tuned universes in a multiverse. The univon, also called a cosmic quantum, is composed of a helically circulating superluminal primordial information quantum (sprinq). [(The univon is the quantum particle of a conscious cosmic quantum field having both physical and mental potentialities. Quantum fields may be composed of cosmic ectoplasm or mind-stuff, which according to yoga philosophy is a subtle vibrational substance formed from consciousness by a cosmic creative power, that takes the form of objects within a cosmic mind)]. The physical [(and mind-stuff)] constants carried in the information content of each univon's sprinq are exactly the same in all univons and in all sprinqs, though sprinqs express different fundamental particle attributes in different environments. The univon is radioactive. The decay of a univon into less energetic products is the starting point $(\mathrm{t}=0)$ of its created universe. The univon's sprinq rapidly multiplies itself into different quantum fields and particles, leading very quickly to the early universe's exponentially-rapid inflationary period and then to the Big Bang, which produces abundant relic dark matter particles of the universe as well as the less abundant ordinary matter. Univons made many other [(entangling)] equally fine-tuned universes with identical fundamental forces and constants.... (pgs. 1-3).

In my metaphysical materialistic model, which differs in language and the need for a "cosmic mind," the "univon" is the cosmological scale described by Einstein constituted by the forces, constants, particles, etc., sprinqs in Gauthier's hypothesis and phenomenal properties or qualia in my model, of the multiverses, with gravity and the psychionic force of consciousness emergent forces following matter aggregation, evolution, and disaggregation, which give rise to inflation, big bangs, and additional (entangled) universes with similar informational (physical and mental) content. Hence, the mathematics for both models are the same as seen in Figures 1 and 2, which is adopted from Gauthier (2020). I tie this physical model to Mocombe's structuration theory, phenomenological structuralism, to explain the emergence and constitution of the multiverses, consciousness, minds, and society in them (Figure 1,2).

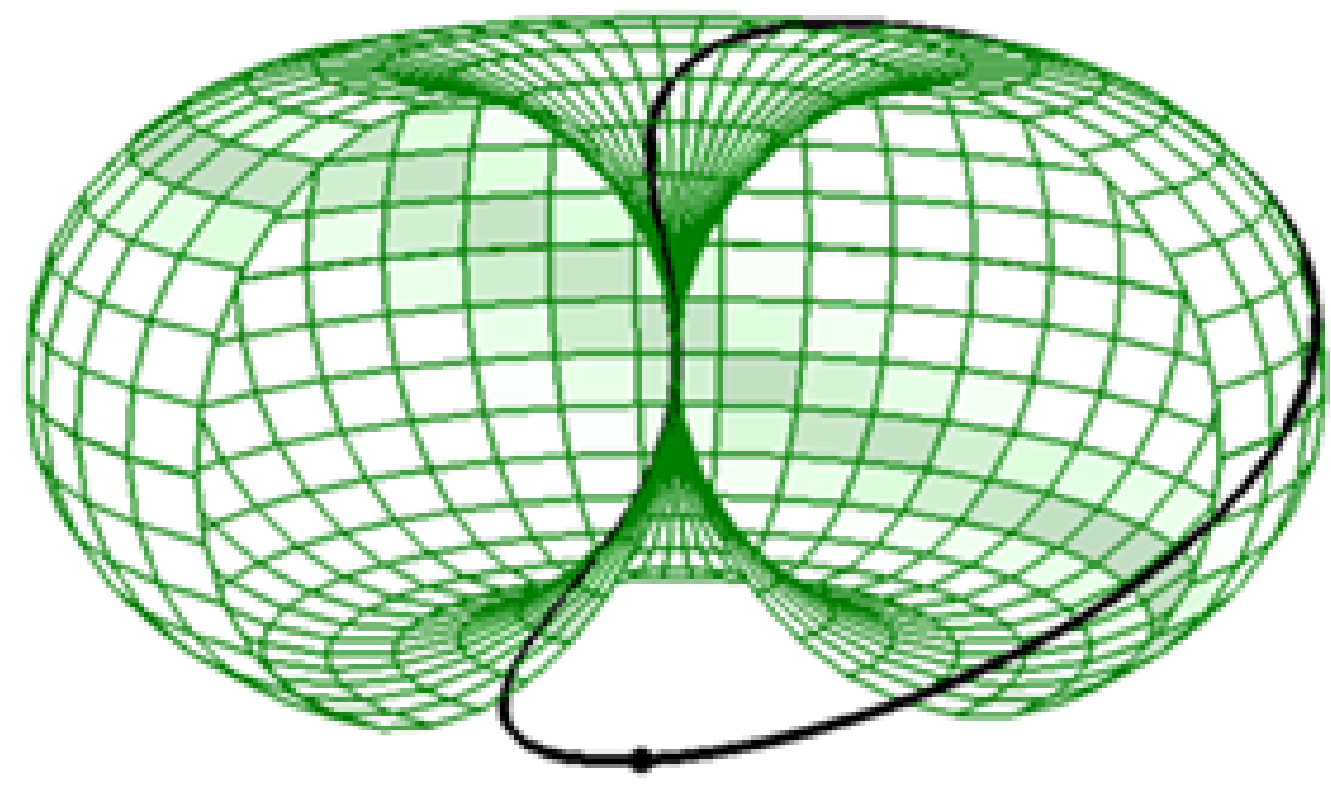

Figure 1: the Univon model composed of a superluminal primordial information quantum (sprinq). The mathematical horn torus surface on which the sprinq is cut away to show the interior. Tha black closed curve on the surface of the horn torus is the trajectory of the Univou's sprinq(indicated by the black dot.) 


$$
\begin{gathered}
x(t)=R(1+\cos (\omega t)) \cos (\omega t) \\
y(t)=R(1+\cos (\omega t)) \sin (\omega t) \\
z(t)=R \sin (\omega t) \\
R=\hbar / M c=2.9 \times 10^{-97} \mathrm{~m} \\
\omega=M c^{2} / \hbar=1.0 \times 10^{105} \text { radians } / \mathrm{s} \\
M=\text { mass of observable universe }=1.2 \times 10^{54} \mathrm{~kg}
\end{gathered}
$$

Figure 2: The parametric equations of the univon model composed of a circulating sprinq. The calculated maximum speed of the circulating sprinq is c square root $(5)=2.236 \mathrm{c}$ (at the equator of the mathematical torus) when it is minimum speed is $\mathrm{c}$ (at the center of the mathematical torus).

\section{Structurationism and Phenomenological Structuralism}

To the aforementioned physical and metaphysical processes, I add the sociology of structuration theory to account for the emergence of human action and its relation to consciousness in the determinism of the multiverses and the constitution of societies. Structurationist sociology synthesizes structure and agency via the concept of praxis or practical consciousness; accounting for human agency or practical consciousness via the actions associated with (societal) structural reproduction and differentiation within a particular material resource framework (Crothers, 2003; Ortner, 1984). This latter factor, however, does not account for the moments or movements, which escape from the compound of socially constructed identifications, which for Mocombe is epiphenomenal. Building on structurationist sociology in relation to the physics and metaphysics of phenomenological structuralism, Mocombe argues that the "moments, or movements, which escape from the compound of socially constructed identifications" are the product of an individual actors' (mental) stance/analytics (Martin Heidegger's term) vis-à-vis three types of structures/systems of signification amidst the practical consciousness associated with societal structural reproduction and differentiation (the social system): 1) the (chemical, biological, and physiological) drives (forms of sensibility and understanding) of the body and brain (the biological system),2) impulses or phenomenal properties of residual past/present/future consciousnesses or recycled/entangled/ superimposed subatomic/chemical particles encapsulated in and as the neuronal energies of the brain via microtubules (the physical system), 3) and actions or practical consciousnesses resulting from the deferment of meaning in ego-centered linguistic and symbolic communicative discourse (the linguistic system). Our ability to perform the latter, defer meaning in ego-centered communicative discourse, is what gives us as a species the illusion of choice and free-will amidst the aforementioned determining structures the second of which is tied to our connection to the (physical) multiverse and its constitution [10-15].

Generally speaking, consciousnesses, actions (practical consciousness), learning, and development within Mocombe's phenomenological structural ontology are the product of the embodiment of the phenomenal properties, qualia, of recycled/ entangled/superimposed subatomic neuronal energies/chemicals, psychion, of the multiverse objectified in the space-time of multiverses via the aggregated body and the microtubules of the brain. Once objectified and embodied the phenomenal properties, qualia, of the neuronal energies/chemicals encounter the space-time of physical worlds via a transcendental subject of consciousnesses (the aggregation of a universal-self superimposed and entangled across the multiple worlds of the multiverse) and the drives and sensibilities of the aggregated body and brain in reified structures of signification, language, ideology, ideological apparatuses, and communicative discourse defined and determined by other beings that control the resources (economics), and modes of distributing them, of the material world required for physical survival in spacetime. The Heideggerian (mental) stances/analytics, "ready-tohand," "unready-to-hand," and "present-at-hand," which emerge as a result of conflict between the embodied transcendental ego vis-à-vis its different (structuring) systems, 1) the sensibilities and (chemical, biological, and physiological) drives of the body and brain, 2) drives/impulses of embodied residual memories or phenomenal properties of past/present/future recycled/ entangled/superimposed subatomic/chemical particles, 3) the actions produced via the body in relation to the indeterminacy/ deferment of meaning of linguistic and symbolic signifiers as they appear to individuated consciousnesses in ego-centered communicative discourse, 4) and the dialectical and differentiating effects, i.e., structural reproduction and differentiation, of the structures of signification, social class language game, of those who control the economic materials (and their distribution, i.e., mode of production) of a world are the origins of practical consciousnesses. All four types of actions, the drives and sensibilities of the body and brain, drives or phenomenal properties of embodied recycled/ entangled/superimposed past/present/future consciousnesses, structural reproduction/differentiation stemming from the mode of production, and deferential actions arising from the deferment of meaning in ego-centered communicative discourse via the present-at-hand stance/analytic, exist in the material world with the social class language game, i.e., the physical, mental, emotional, ideological, etc. 5) powers of those who control the material resource framework as the causative agent for individual behaviors. 
In other words, our (mental) stances in consciousness vis-à-vis the conflict between the (chemical, biological, and physiological) drives and sensibilities of the body and brain, (societal) structural reproduction and differentiation, drives of embodied past/present/ future consciousnesses of recycled/entangled/superimposed subatomic/chemical particles, and deferential actions arising as a result of the deferment of meaning in ego-centered communicative discourse determines the practical consciousness we want to recursively reorganize and reproduce in the material world. The power, power positions, and power relations of those who control (via the mode of production, language, ideology, ideological apparatuses, and communicative discourse) the resources (and their distribution, i.e., mode of production) of a material resource framework, and the threat it poses to the ontological security of an actor, in the end determines what actions and identities are allowed to organize and reproduce in the material world without the individual actor/agent facing marginalization or death [16-20].

It is Being's (mental) stance/analytic, "ready-to-hand," "unready-to-hand," and "present-at-hand," in consciousness vis-àvis the conflict, or lack thereof, between the (chemical, biological, and physiological) drives and sensibilities of the aggregated body and brain, drives/impulses (phenomenal properties) of residual past/present/future consciousnesses of recycled/entangled/ superimposed subatomic particles, alternative practices which arise as a result of phenomenological meditation and deferment of meaning, along with the differentiating logic or class divisions of the social relations of production, which produces the variability of actions and practices in cultures, social structures, or social systems and gives us the illusion of free-will. All four types of actions are always present and manifested in a social structure to some degree contingent upon the will and desires of the economic social class, power elites, which controls the material resource framework through its body (practical consciousness), language/ symbols, ideology, ideological apparatuses, and social relations of production. They choose, amidst the class division of the social relations of production, what other meaning constitutions and practices manifest themselves in the material world without facing alienation, marginalization, domination, or death.

Hence, we never experience the things-in-themselves of the world culturally and historically in consciousness. We experience them structurally or relationally, the structure of the conjuncture of the mode of production, its language, ideology, ideological apparatuses, etc., and our (mental) stances/analytics, ready-tohand, unready-to-hand, present-at-hand, vis-à-vis these things as they appear to and in consciousness determine our practical consciousness or behaviors [21-25].

We initially know, experience, and utilize the things of and in consciousness in the preontological ready-to-hand mode, which is structural and relational. That is, our bodies encounter, know, experience, and utilize the things of the world in consciousness, intersubjectively, via their representation as objects of knowledge, truth, usage, and experience enframed and defined in the relational logic and practices or language game (Wittgenstein's term) of the institutions or ideological apparatuses of the other beings-ofthe-material resource framework whose historicity comes before our own and gets reified in and as the actions of their bodies, language, ideology, ideological apparatuses, mode of production, and communicative discourse. This is the predefined phenomenal structural, i.e., ontological, world we and our bodies are thrown-in in coming to be-in-the-world. How an embodied-hermeneuticallystructured Being as such solipsistically view, experience, understand, act, and utilize the predefined objects of knowledge, truth, and experienced defined by others and their conditions of possibilities in consciousness in order to formulate their practical consciousness is albeit indeterminate. Martin Heidegger in Being in Time is accurate, however, in suggesting that three stances or modes of encounter (Analytic of Dasein), "presence-at-hand," "readiness-to-hand," and "un-readiness-to-hand," characterizes our views of the things of consciousness represented intersubjectively via bodies, language, ideology, and communicative discourse, and subsequently determine our practical consciousness or social agency. In "ready-to-hand," which is the preontological mode of human existence thrown in the world, we accept and use the things in consciousness with no conscious experience of them, i.e., without thinking about them or giving them any meaning or signification outside of their intended usage. Heidegger's example is that of using a hammer in hammering. We use a hammer without thinking about it or giving it any other condition of possibility outside of its intended usage as defined by those whose historicity presupposes our own. In "present-at-hand," which, according to Heidegger, is the stance of science, we objectify the things of consciousness and attempt to determine and reify their meanings, usage, and conditions of possibilities as the nature of reality as such. Hence the hammer is intended for hammering by those who created it as a thing solely meant as such. The "unready-to-hand" outlook is assumed when something goes wrong in our usage of a thing of consciousness as defined and determined by those who adopt a "present-at-hand" view. As in the case of the hammer, the unreadyto-hand view is assumed when the hammer breaks and we must objectify it, by then assuming a present-at-hand position, and think about it in order to either reconstitute it as a hammer, or give it another condition of possibility. Any other condition of possibility that we give the hammer outside of its initial condition of possibility which presupposed our historicity becomes relational, defined in relation to any of its other conditions of possibilities it may have been given by others we exist in the world with who either readyto-hand, unready-to-hand, or present-at-hand attempts to maintain the social class language game of power. In the ready-to-hand stance the latter unconsciously practices and attempts to reproduce the social class language game of power by discriminating against and marginalizing any other conditions of possibilities of their social class language as determined by those in ideological power positions. They may move to the unready-to-hand stance 
in response to those who they encounter that attempts, presentat-hand, to alter the nature of the dominant social class language game they recursively reorganize and reproduce as outlined by those in power positions who are present-at-hand of the dominant social class language game. In either case, not all beings achieve the present-at-hand stance. The latter is the stance of science and ideologies, which are tautologies when they profess that their stances represent the nature of reality as such, and those in power positions, who choose, among a plethora of alternative presentat-hand social class language games, what alternative practical consciousnesses outside of their social class language game that are allowed to manifest in the material world [26-30].

\section{Discussion and Conclusion}

Hence, as outlined above, phenomenological structuralism posits consciousness to be the by-product or evolution of subatomic particles, psychion, with phenomenal properties, qualia, unfolding with increasing levels of abstraction within entangled and superimposed material resource frameworks enframed by the mode of production, language, ideology, ideological apparatuses, and communicative discourse (i.e., social class language game) of bodies recursively reorganizing and reproducing the ideals of the latter factors as their practical consciousness. That is to say, the logical consequence regarding the evolution and constitution of the multiverses, and their contents, based on the assumptions of superposition, action-at-a-distance, wave-function realism, phenomenal properties, and panpsychism of quantum mechanics, for Mocombe, is similar to the intersecting worlds theory highlighted in Haitian Vodou, which parallels the physics, "membrane theory," of Lisa Randall and Raman Sundrum (1999). The proposal in keeping with the logic of Haitian Vodou and the "brane theory" of Randall and Sundrum is that there might be an additional dimension on the cosmological scale, the scale described by general relativity, which gives rise to four dimensional multiverses within it. That is to say, our universe is embedded in a vastly bigger five-dimensional space (the four-dimensional space of relativity, plus a fifth dimension for the subatomic forces including consciousness), a kind of superuniverse. Within this super-space, our universe is just one of a whole array of co-existing, entangled, and superimposed universes (Haitian Vodou only accounts for our universe and its parallel), each a separate four-dimensional bubble, which share the same informational contents via black holes, within a wider arena of five-dimensional space where consciousness (a subatomic force, i.e., psychion, and its phenomenal properties, qualia) is recycled/ entangled/superimposed between the five-dimensional superspace, i.e., superverses, and their multiverses.


Figure 3: For Mocombe, the superverses with entangled and superimposed (via black holes) multiverses share the same informational content. So, the hypothesis here is that one superverse created a universe, and its informational content is entangled and superimposed on top of another superverse with the informational content of the previous universe emerging in it via black holes. Hence what you have is a layer of multiverses and superverses, superimposed and entangled, whose informational content is shared or recycled via black holes, which organize and structure the multiverses similarly. As such, quantum fluctuation and big bangs are constantly occurring and producing the same worlds, ad infinitum. So, when physicists look out to the cosmic microwave background (CMB), they are looking at the remnant from an early stage of our universe, which came forth from its older version a layer above it, and so on ad infinitum. Put more concretely, the physicists are in a superverse, of our universe, in our milky-way galaxy, looking out to the black hole of a milky-way galaxy from the superverse/multiverse above us. 
For Mocombe the multiverses originated, from the superuniverses, either by fiat or quantum fluctuation. They are bosonic forces that were brought forth together with fermion counterparts. They are also the primeval pan-psychic fields, stemming from the superimposed and entangled super-verses, whose fermion can be called a psychion, a particle of consciousness or proto-consciousness. These have evolved together to produce the four forces of nature, electromagnetic force; gravity; the strong nuclear force; and weak nuclear force, in our universe, which in turn produced atoms, molecules, and aggregated life endowed (embodied) with the recycled/entangled/superimposed consciousness and phenomenal properties, qualia or informational content, of the primeval pan-psychic fields, psychion (the fifth force of nature), of the superverses and their multiverses. In other words, the superverses with entangled and superimposed (via black holes) multiverses share the same informational content. So, the hypothesis here is that one (original) superverse created a universe, and its informational content is entangled and superimposed on top of another superverse with the informational content of the previous universe emerging in it via black holes. Hence what you have are a layer of multiverses and superverses, superimposed and entangled, whose informational content is shared or recycled via black holes, which organize and structure the multiverses similarly. As such, quantum fluctuation and big bangs are constantly occurring and producing the same worlds, superimposed and entangled, ad infinitum. So, when physicists look out to the cosmic microwave background (CMB), they are looking at the remnant from an early stage of our universe, which came forth from its older version a layer above it, and so on ad infinitum (see Figure 3). Put more concretely, the physicists are in a superverse, of our universe, in our milky-way galaxy, looking out to the black hole of a milky-way galaxy from the superverse/multiverse above us [31-38].

Within these same worlds or multiverses, subatomic particles, via the Higgs boson particle, give/gave rise to carbon atoms, molecules and chemistry, which give/gave rise to DNA, biological organisms, neurons and nervous systems, which aggregate/ aggregated into bodies and brains that give/gave rise to the embodiment of preexisting consciousness of the subatomic particles, bodies, and languages from entangled/superimposed multiverses. In human beings, the indeterminate behavior of superimposed and entangled subatomic neuronal energies that produced the plethora of consciousnesses and languages in the neocortex of brains gave rise to ideologies, which in turn gave rise to ideological apparatuses and societies (sociology) under the social class language game or language, ideology, and ideological apparatuses of those who organize and control the material resources (and their distribution) required for physical (embodied) survival in a particular resource framework. So contrary to Karl Marx's materialism which posits human consciousness to be the product of material conditions, the logic here is a structural Marxist one in the Althusserian sense. That is, the aggregated, atomic, mature human being is a body and neuronal drives that never encounters the (ontological) material world directly. Instead, they encounter the (ideological) world via structures of signification, which structures the world or a particular part of it through the body, language, ideology, ideological apparatuses, and communicative discourse, i.e., social class language game, of those whose power, power positions, and power relations dictate how the resources of that framework are to be gathered, used, and distributed (means and mode of production) [36-38].

Hence in the end, societal and subject constitution, mind organizing and reproducing consciousness as praxis, is a product of conflict and an individual's mental stance, i.e., analytics, vis-àvis three structures/systems of signification and the ability to defer meaning in ego-centered communicative discourse stemming from the social class language game (i.e., language, symbols, ideology, ideological apparatuses, and communicative discourse) of those who control the mode of production of a material resource framework. It is the ready-to-hand drives of the body and brain, ready-to-hand and present-at-hand manifestation of past/present/ future recycled residual consciousnesses/subatomic particles, the present-at-hand phenomenological meditation and deferment of meaning that occurs in embodied consciousness via language, ideology, and communicative discourse as reflected in diverse individual practices, within the ready-to-hand, unready-to-hand, and present-at-hand differentiating logic or class divisions of the social relations of production, which produces the variability of actions and practices in cultures, social structures, or social systems. All four types of actions, the (chemical, biological, and physiological) drives/impulses of the body and residual past consciousnesses of subatomic particles, structural reproduction/differentiation, and actions resulting from the deferment of meaning in ego-centered communicative discourse, are always present and manifested in a social structure (which is the reified ideology via ideological apparatuses, their social class language game, of those who control a material resource framework) to some degree contingent upon the will and desires of the economic social class that controls the material resource framework through the actions of their bodies (practical consciousness), language, symbols, ideology, ideological apparatuses, and social relations of production. They choose, amidst the class division of the social relations of production, "the structure of the conjuncture," (Marshall Sahlins's term) what other meaning constitutions and practices are allowed to manifest themselves without the Beings of that practice facing alienation, marginalization, domination, or death.

The individual being is initially constituted as superimposed, entangled, recycled, and embodied subatomic particles, psychion, of multiple worlds of the multiverse, which have their own predetermined form of understanding and cognition, phenomenal properties, qualia, based on previous or simultaneous experiences as aggregated matter (this is akin to what the Greek philosopher 
Plato refers to when he posits knowledge as recollection of the Soul). Again, the individual's actions are not necessarily determined by the embodiment and drives of these recycled/ entangled/superimposed subatomic particles. It is conflict and an individual's stance, ready-to-hand, unready-to-hand, and presentat-hand, when the subatomic particles become aggregated matter or embodied, which determines whether are not they become aware, present-at-hand, of the subatomic particle drives and choose to recursively reorganize and reproduce the content of the drives as their practical consciousness.

This desire to reproduce the cognition and understanding of the (chemical, biological, and physiological) drives of the recycled/ entangled/superimposed subatomic particles, however, may be limited by the structuring structure of the aggregated body and brain of the individual subject. That is to say, the second origins and basis of an individual's actions are the structuring drives and desires, for food, clothing, shelter, social interaction, and sex, of the aggregated body and brain, which the subatomic particles constitute and embody. In other words, the aggregated body and brain is preprogrammed with its own (biological) forms of sensibility, understanding, and cognition, structuring structure, by which it experiences being-in-the-world as aggregated embodied subatomic particles. These bodily forms of sensibility, understanding, and cognition, such as the drive and desire for food, clothing, shelter, social interaction, linguistic communication, and sex, are tied to the material embodiment and survival of the embodied individual actor, and may or may not supersede or conflict with the desire and drive of an individual to recursively (re) organize and reproduce the structuring structure of the superimposed, entangled, and recycled (phenomenal properties of) subatomic particles. If these two initial structuring structures are in conflict, the individual moves from the ready-to-hand to the unready-to-hand stance or analytics where they may begin to reflect upon and question their being-in-theworld prior to acting. Hence just as in the case of the structuring structure of the subatomic particles it is an individual being's analytics vis-à-vis the drives of its body and brain in relation to the impulses of the subatomic particles, which determines whether or not they become driven by the desire to solely fulfill the material needs of their body and brain at the expense of the drives/desires of the subatomic particles or the social class language game of the material resource framework they find their existence unfolding in.

The social class language game, and its differentiating effects, an individual find their existence unfolding in is the third structuring structure, which attempts to determine the actions of individual beings as they experience being-in-the-world as embodied subatomic particles. The aggregated individual finds themselves objectified and unfolding within a material resource framework controlled by the actions of other bodies, which presuppose their existence, via the actions of their bodies (practical consciousness), language, communicative discourse, ideology, and ideological apparatuses stemming from how they satisfy the desires of their bodies and subatomic particle drives (means and mode of production). What is aggregated as a social class language game by those in power positions via and within its mode of production, language, ideology, ideological apparatuses, and communicative discourse attempts to interpellate and subjectify other beings to its interpretive frame of satisfying their bodily needs, fulfilling the impulses of their subatomic particles, and organizing a material resource framework at the expense of all others, and becomes a third form of structuring individual action based on the mode of production and how it differentiates individual actors.

That is to say, an individual's interpellation, subjectification, and differentiation within the social class language game that presupposes their being-in-a-world attempts to determine their actions or practical consciousness via the reified language, ideology, etc., of the social class language game, the meaning of which can be deferred via the communicative discourse of the individual actors allowing them to form social groups or heterogeneous communities tied to the dominant social order because of their control of the materials of the material resource framework. Hence, the deferment of meaning in ego-centered communicative discourse of the language and ideology of a social class language game is the final means of determining an individual's action or practical consciousness outside of, and in relation to, its stance, i.e., analytics, vis-à-vis the drives of subatomic particles, drives and desires of the body and brain, and structural reproduction and differentiation. The (mental) stance of the transcendental ego and the ability to defer meaning in ego-centered communicative discourse within a social class language game are what accounts for the feeling or illusion of free-will.

In other words, whereas the practical consciousness of the transcendental ego stemming from the impulses of embodied subatomic particles are indeterminant as with its neuronal processes involved with the constitution of meaning in ego-centered communicative discourse (Albeit physicists are in the process of exploring the nature, origins, and final states of subatomic particles, and neuroscientists are attempting to understand the role of neuronal activities in developing the transcendental ego and whether or not it continues to exist after death). The form of the understandings and sensibilities of the body and brain are determinant as with structural reproduction and differentiation of the mode of production, and therefore can be mapped out by neuroscientists, biologists, and sociologists to determine the nature, origins, and directions of societal constitution and an individual actor's practical consciousness unfolding.

The interaction of all four elements or processes in relation to the (mental) stance of the transcendental ego of the individual actor is the basis for human action, praxis/practical consciousness, and cognition/mind in a world. However, in the end, consequently, the majority of practical consciousness will be a product of an individual actor's embodiment and the structural reproduction 
and differentiation of a social class language game given 1) the determinant nature of embodiment, form of understanding and sensibility of the body and brain amidst, paradoxically, the indeterminacy of impulses of embodied subatomic particles and the neuronal processes involved in ego-centered communicative discourse; and 2) the consolidation of power of those who control the material resource framework wherein a society, the social class language game, is ensconced and the threat that power (consolidated and constituted via the actions of bodies, mode of production, language, ideology, ideological apparatuses, and communicative discourse) poses to the ontological security of an aggregated individual actor who chooses (or not) either ready-tohand or present-at-hand to recursively reorganize and reproduce the ideals of the society as their practical consciousness. It should be mentioned that in response to this latter process, those in power positions who internalize the ideals of the social structure and recursively (re) organize and reproduce them as their practical consciousness are in the unready-to-hand stance when they encounter alternative forms of being-in-the-world within their social class language game. They dialectically attempt to reconcile the practical consciousness of their social class language game with the reified practical consciousness of those who have deferred their meanings for alternative forms of being-in-the-world within their social class language. They can either accept, marginalize, or seek to eradicate the deferred or decentered subject or their practices.

Hence, in Paul C. Mocombe's conception of the multiverse, "the theory of phenomenological structuralism," libertarian free-will is an illusion, and a product of the human ability to defer meaning in ego-centered communicative discourse, to name and exercise the practical consciousness stemming from the determining structures/systems, unfolding throughout the multiverse. In other words, for Mocombe, the multiverse is deterministic and every option we choose to manifest as our praxis plays out in alternate multiverses until the choices extinguish the life of our being and said multiverse. Hence, for Mocombe the free will/determinism debate is tied to language, consciousness, and epistemology. In other words, the human species is determined by three structures of signification and the mental stance/analytic of consciousness, the impulses of phenomenal property, the anatomical and physiological drives of the body, and structural reproduction and differentiation. As we experience being-in-the-world with those who control the resources of the material resource framework, i.e., the world, our mental stance vis-à-vis the language of communicative discourse and action is the sole basis for the illusion of free-will. That is, in communicating the discourse and action of the social structure individual human actors are able to defer meaning in ego-centered communicate discourse for alternative meanings and actions, tied to the aforementioned structuring structures, which they may reproduce as their practical consciousness in a discriminated against precarious position (i.e., a discriminated against other) in the social structure. Their meanings and practical consciousnesses are an illusion of free-will in the sense that their chosen deferred meanings and actions both are the product of the determining antecedents or structuring structures highlighted above, and their opening-up of other lines of their existence in the multiverse based on their corresponding actions. That is to say, for every chosen choice, from the determining structures with their corresponding actions, a line of existence in the multiverse is opened and runs parallel to the original or originating line of existence. Individual human existence, choices, and actions are all accounted and determined for in the multiverse, all pointing or leading to one ultimate predetermined end, which is determinate and unalterable. As such, human existence should follow the patterned actions of all other species, which is maintaining balance and harmony between the material resource framework and satisfying everyday anatomical and physiological needs and drives for subsistence living.

Future research must continue to search for multiverses and other forms of existence tied to our present world, which will be similarly constituted as our own universe, in order to falsify or verify Mocombe's overall theory of phenomenological structuralism (Figure 3).

\section{Acknowledgement}

None.

\section{Conflicts of Interest}

No conflicts of interest.

\section{References}

1. Gauthier, Richard (2020) Big Bangs Created by Univon Particles from a Conscious Quantum Field-Towards the Next Scientific Revolution.

2. Mocombe, Paul C (2019) The Theory of Phenomenological Structuralism. United Kingdom: Cambridge Scholars Publishing.

3. Hameroff, Stuart and Roger Penrose (2014) Consciousness in the Universe: A Review of the 'Orch OR' theory. Physics of Life Reviews 11: 39-78.

4. Mocombe, Paul C (2016) The Vodou Ethic and the Spirit of Communism: The Practical Consciousness of the African People of Haiti. Maryland: University Press of America.

5. Althusser, Louis (2001) Lenin and Philosophy and Other Essays. New York: Monthly Review Press.

6. Althusser, Louis, Etienne Balibar (1970) Reading Capital (Ben Brewster Trans. London: NLB.

7. Balibar, Etienne, Immanuel Wallerstein (1991) Race, Nation, Class: Ambiguous Identities. London: Verso.

8. Buck-Morss, Susan (2009) Hegel, Haiti, and Universal History. Pittsburgh: University of Pittsburgh Press.

9. Cohen J (2002) Protestantism and Capitalism: The Mechanisms of Influence. New York: Aldine de Gruyter.

10. Crothers, Charles (2003) Technical Advances in General Sociological Theory: The Potential Contribution of Post-Structurationist Sociology. Perspectives, 26(3): 3-6.

11. Dahrendorf Ralf (1959) Class and Class Conflict in Industrial Society. Stanford, California: Stanford University Press. 
12. Douglas M (1986) How Institutions Think. New York: Syracuse University Press. Fraser, Nancy (1997) Justice Interruptus: Critical Reflections on the "Postsocialist" Condition. New York \& London: Routledge.

13. Holloway, Joseph E (ed.) (1990a) Africanisms in American Culture. Bloomington and Indianapolis: Indiana University Press.

14. Holloway, Joseph E (1990b) The Origins of African American Culture. In Joseph Holloway (Ed.), Africanisms in American Culture (19-33).

15. Bloomington and Indianapolis: Indiana University Press.

16. Horkheimer Max, Theodor W Adorno (2000) Dialectic of Enlightenment (John Cumming, Trans.). New York: Continuum.

17. Hudson, Kenneth and Andrea Coukos (2005) The Dark Side of the Protestant Ethic: A Comparative Analysis of Welfare Reform. Sociological Theory 23 (1): 1-24.

18. James, CLR (1986) The Black Jacobins: Toussaint L' Ouverture and the San Domingo Revolution Vintage.

19. Karenga, Maulana (1993) Introduction to Black Studies. California: The University of Sankore Press.

20. Kellner, Douglas (2002) Theorizing Globalization. Sociological Theory 20(3): 285-305.

21. Kurtz, Lester R. (2007) Gods in the Global Village: The World's Religions in Sociological Perspective. California: Sage Publications.

22. Lukacs, Georg (1971) History and Class Consciousness: Studies in Marxist Dialectics (Rodney Livingstone, Trans) Cambridge, Massachusetts: The MIT Press.

23. Lukacs, Georg (2000) A Defence of History and Class Consciousness: Tailism and the Dialectic (Esther Leslie, Trans). London and New York: Verso.

24. Marcuse, Herbert (1964) One-Dimensional Man. Boston: Beacon Press.

25. Marcuse, Herbert (1974) Eros and Civilization: A Philosophical Inquiry into Freud. Boston: Beacon Press.
26. Marx, Karl and Friedrich Engels (1964) The Communist Manifesto. London, England: Penguin Books.

27. Marx, Karl (1992) Capital: A Critique of Political Economy (Volume 1, Samuel Moore and Edward Aveling, Trans.). New York: International Publishers.

28. Marx, Karl (1998) The German Ideology. New York: Prometheus Books.

29. McMichael, Philip (2008) Development and Social Change: A Global Perspective. Los Angeles, California: Sage Publications.

30. Mocombe, Paul C (2009) The Soul-less Souls of Black Folk: A Sociological Reconsideration of Black Consciousness as Du Boisian Double Consciousness. Maryland: University Press of America.

31. Ortner, Sherry (1984) Theory in Anthropology Since the Sixties, Comparative Studies in Society and History 26: 126-66.

32. Patterson, Orlando (1982) Slavery and Social Death: A Comparative Study. Cambridge, Massachusetts: Harvard University Press.

33. Ramsey, Kate (2011) The Spirits and the Law: Vodou and Power in Haiti. Chicago: University of Chicago Press.

34. Rubin, Vera (Ed.) (1960) Caribbean Studies: A Symposium. Seattle: University of Washington Press.

35. Sklair, Leslie (1995) Sociology of the Global System. Baltimore: Westview Press. Smith M.G. (1960). The African Heritage in the Caribbean.

36. In Vera Rubin (Ed.) (1982) Caribbean Studies: A Symposium Seattle: University of Washington Press. Wallerstein, Immanuel p.34-46.

37. The Rise and Future Demise of the World Capitalist System: Concepts for Comparative Analysis. In Hamza Alavi and Teodor Shanin (Eds.) Introduction to the Sociology of Developing Societies. New York: Monthly Review Press p. 29-53

38. Weber, Max (1958) The Protestant Ethic and the Spirit of Capitalism (Talcott Parsons, Trans). New York: Charles Scribner's Sons. 